CLINICAL STUDY

\title{
Acromegaly per se does not increase the risk for coronary artery disease
}

\author{
Hiroyoshi Akutsu ${ }^{1}$, Jürgen Kreutzer ${ }^{1}$, Gerald Wasmeier ${ }^{3}$, Dieter Ropers ${ }^{3}$, Christian Rost ${ }^{3}$, Matthias Möhlig ${ }^{4}$, \\ Henri Wallaschofski ${ }^{5}$, Michael Buchfelder ${ }^{1}$ and Christof Schöfl ${ }^{1,2}$ \\ ${ }^{1}$ Department of Neurosurgery, ${ }^{2}$ Division of Neuroendocrinology and ${ }^{3}$ Department of Cardiology and Angiology, Friedrich-Alexander-University Erlangen- \\ Nuremberg, Schwabachanlage 6, 91054 Erlangen, Germany, ${ }^{4}$ Department of Endocrinology, Diabetes and Nutrition, Charité University-Medicine Berlin, \\ 12200 Berlin, Germany and ${ }^{5}$ Department of Clinical Chemistry and Laboratory Medicine, Ernst-Moritz Arndt University, 17475 Greifswald, Germany \\ (Correspondence should be addressed to C Schöfl at Division of Neuroendocrinology, Department of Neurosurgery, Friedrich-Alexander-University of \\ Erlangen-Nuremberg; Email: christof.schoefl@uk-erlangen.de)
}

\begin{abstract}
Context: Information about the risk and course of coronary artery disease (CAD) in acromegaly is limited.

Objective: To evaluate CAD risk in acromegalic patients at diagnosis and after successful treatment during follow-up.

Subjects and methods: Twenty-five consecutive patients (age $45.1 \pm 10.6$ years, 15 women) were studied at the time of diagnosis, and 19 patients were re-evaluated after $4.6 \pm 1.1$ years. The European Society of Cardiology (ESC) risk score was calculated, and a cardiac computed tomography was performed for detection and quantification (Agatston score (AS)) of coronary artery calcium (CACs). Fifty age-, sex-, and CAD risk-matched subjects and CAC data from the population-based Heinz Nixdorf Recall (HNR) study served as controls.

Results: In 21 of the 25 patients, the 10-year risk of developing CAD according to the ESC risk score was low $(<10 \%)$ and high $(>20 \%)$ in four patients. The AS was lower than in controls $(2.6 \pm 7.9$ vs $66 \pm 182 ; P=0.014)$ and less patients had a positive CAC (AS $>0)(20$ vs $48 \%, P=0.024)$, which in the acromegalic patients was less than expected from the HNR study. The AS did not correlate with GH excess or disease duration. In 19 acromegalic patients, who were in remission and re-evaluated after $4.6 \pm 1.1$ years, the ESC risk $(P=0.102)$ and the AS $(P=0.173)$ did not change significantly and no symptomatic CAD event occurred.

Conclusion: CAD risk in newly diagnosed acromegalic patients was low and remained stable after successful treatment. CAC was lower than in controls suggesting that GH excess per se does not carry an additional CAD risk.
\end{abstract}

European Journal of Endocrinology 162 879-886

\section{Introduction}

Acromegaly is characterized by $\mathrm{GH}$ excess, which in most cases is caused by a GH-secreting pituitary adenoma. The disease is associated with an increased mortality $(1,2)$. Cardiovascular events are the leading cause of death, which are directly related to $\mathrm{GH}$ and/or consecutive insulin-like growth factor 1 (IGF1) excess $(1,2)$. Acromegalic cardiomyopathy is a typical and frequent complication of chronic GH excess, which is characterized by a concentric biventricular hypertrophy, impairment of diastolic function, and mitral and aortic valve disease (3-6). In addition, coronary artery disease (CAD) may contribute to the cardiac phenotype in acromegalic patients as suggested by early pathological studies (6-9). Coronary risk factors like hypertension, insulin resistance, diabetes mellitus, and dyslipidemia are frequent complications of acromegaly, thus providing a possible link between GH hypersecretion and CAD $(1,5)$. Furthermore, GH and IGF excess per se, at least in part, may cause functional and morphological vascular alterations (10). IGFs are potent mitogens for vascular smooth muscle cells (11), and IGF1 stimulates the expression of adhesion molecules (12), a feature of endothelial dysfunction. On the other hand, there are studies questioning an increased prevalence of $\mathrm{CAD}$ in patients with acromegaly or even suggesting an antiatherogenic effect of GH-IGF1 excess $(9,13)$. In one cross-sectional study, the integrated evaluation of the Framingham risk score (FS) and coronary artery calcium (CAC) as assessed by multidetector computed tomography (CT) showed that 
$41 \%$ of acromegalics were at risk for atherosclerosis (14). The control of acromegaly, however, did not influence the extent of coronary atherosclerosis, and the study provided indirect evidence that calcium deposits may not progress in acromegaly as in the general population, which would be consistent with a protective effect of GH excess (14). In another prospective study, the risk of $\mathrm{CAD}$ was low, and none of the acromegalic patients developed a major cardiac event during the 5-year study period (15). Together, the data on CAD in acromegaly are limited, controversial, mainly refer to older pathological studies or are based on mixed patient populations comprising controlled and uncontrolled acromegaly without controls matched for CAD risk factors $(1,5-9,14-16)$.

In the present study, we evaluated cardiac performance, CAD risk, and CAD as evidenced by computed tomography (CT)-detected CAC in patients with acromegaly at the time of diagnosis and during follow-up. CAC is closely correlated with the presence and extent of atherosclerotic plaques and constitutes a potential noninvasive marker for early stages of coronary atherosclerosis in asymptomatic subjects (17-21). CAC data from acromegalic patients were compared to controls matched for age, sex, and CAD risk factors to evaluate whether $\mathrm{GH}$ and/or IGF1 excess per se modulates $\mathrm{CAD}$ risk. In addition, $\mathrm{CAC}$ data from the population-based Heinz Nixdorf Recall (HNR) study served as a further control (22).

\section{Patients and methods}

\section{Patients}

We prospectively studied 25 consecutive patients with newly diagnosed and untreated acromegaly, who were referred for surgery to the Department of Neurosurgery of the Friedrich-Alexander-University of ErlangenNuremberg, Erlangen, Germany between 2002 and 2004. The diagnosis of acromegaly was made on the basis of typical clinical features, an elevated serum IGF1 level matched for sex and age ( $>2$ s.D.), and lack of suppression of serum $\mathrm{GH}<1 \mathrm{ng} / \mathrm{ml}$ after a 100-g oral glucose tolerance test (OGTT). All patients had a visible pituitary adenoma (five microadenoma and 20 macroadenoma) on magnetic resonance imaging (MRI), and the diagnosis was histologically proven in all cases. The duration of the disease was estimated from the time interval between the onset of symptoms or signs and the diagnosis of acromegaly in years. Three months postoperatively the patients were evaluated by endocrine testing and MRI. If patients were not in remission $(\mathrm{GH}>1 \mathrm{ng} / \mathrm{ml}$ after OGTT and/or elevated IGF1 according to age and sex), medical treatment was started and titrated aiming an IGF1 level within the normal age and sex range $(\leq 2$ s.D). Nineteen of 20 patients who were on routine follow-up at our institution agreed to participate in a second cardiac evaluation. Eleven of the
19 patients $(58 \%)$ were in remission after surgery, ten patients remained in remission during follow-up, and one patient required a further operation after 45 months because of disease recurrence. Six patients were treated with somatostatin analogs (octreotide LAR 20 or $30 \mathrm{mg}$ ), and two patients were on pegvisomant (10-15 mg daily). Three of the eight patients received radiosurgery, and one patient received stereotactic radiotherapy. The study was approved by the Internal Review Board, and all patients gave their informed consent.

\section{Cardiac evaluation and determination of the European Society of Cardiology risk score}

None of the patients complained about angina pectoris or symptoms of cardiac failure, and no patient had a positive history of myocardial infarction on admission or during follow-up. Risk factors like smoking habits, dyslipidemia, diabetes mellitus, hypertension, and a family history for cardiovascular events were assessed. Blood pressure was determined in sitting position after $5 \mathrm{~min}$ of rest; height and weight were measured to calculate the body mass index, and routine clinical chemistry testing including fasting glucose, total cholesterol, and triglycerides was done preoperatively. Hypertension was defined when systolic pressure was $140 \mathrm{mmHg}$ or greater, or diastolic pressure was $90 \mathrm{mmHg}$ or greater (or the patient was on antihypertensive medication); diabetes was diagnosed when fasting serum glucose was $>126 \mathrm{mg} / \mathrm{dl}$ on two occasions (or the patient was taking antidiabetic drugs). Hypercholesterolemia was defined by total cholesterol $\geq 200 \mathrm{mg} / \mathrm{dl}(5.17 \mathrm{mmol} / \mathrm{l}$; or the patient was taking lipid-lowering drugs). Family history was regarded as positive when first-grade relatives had a myocardial or cerebral infarct before the age of 55 years in men (65 years in women). Smoking status was positive when the patient was a current smoker or when he had quitted within the past year.

The risk of developing CAD (nonfatal myocardial infarction or coronary death) over the next 10 years was calculated using the risk tables of the Systematic Coronary Risk Evaluation project of the European Society of Cardiology (ESC) $(23,24)$. Patients were categorized into three risk groups: low $<10 \%$, intermediate $10-20 \%$, and high $>20 \%$ (25).

Echocardiography was performed by an experienced cardiologist according to the American Society of Echocardiography recommendations (26). A conventional second harmonic 2D echo mode with a $2.5-\mathrm{MHz}$ transducer (Vivid 7, General Electric, Horten, Norway) was used for acquisition, and loops were stored for off-line analysis. Echocardiograms were retrospectively re-evaluated by a second experienced cardiologist blinded to the study protocol. Interventricular septum (IVS) thickness and left ventricular posterior wall thickness were measured at end diastole and end systole as defined by electrocardiographic (ECG) tracing. Left ventricular 
mass (LVM) was calculated by using the formula of Devereux \& Reicheck, according to the Penn convention (27). LVM index (LVMi) was determined by the ratio of LVM to body surface area. Left ventricular hypertrophy $(\mathrm{LVH})$ was defined as a LVM of more than $200 \mathrm{~g}$ in men or more than $150 \mathrm{~g}$ in women (26). Left ventricular ejection fraction was calculated semi-automatically using the biplane Simpson's method (26).

Coronary calcium detection scans at baseline were performed using electron beam tomography (C-150XP scanner, GE Imatron Inc., South San Francisco, CA, USA) according to the standard protocol (17). The scanner (tube voltage $130 \mathrm{kV}$ and tube current $44 \mathrm{mAs}$ ) was operated in single-slice mode with acquisition time of $100 \mathrm{~ms}$ and a slice thickness of $3 \mathrm{~mm}$. The follow-up scan was performed using dual-source CT (Definition, Siemens Healthcare Systems, Forchheim, Germany). Data were acquired in spiral mode (collimation $2 \times 64 \times 0.6 \mathrm{~mm}$, tube voltage $120 \mathrm{kV}$, and tube current $100 \mathrm{mAs} / \mathrm{rot}$ ) with retrospective ECG-gated reconstruction at $40 \%$ of the RR interval (28). Axial cross sections of the heart were acquired in inspiratory breathhold with ECG triggering at $40 \%$ of $R$ - to $R$-wave interval. Coronary calcium was assumed to be present if a CT attenuation value of at least $130 \mathrm{HU}$ was found in two or more adjacent pixels, which could be assigned to the coronary artery system. While different scanners and, hence, image acquisition protocols were used for X-ray data acquisition, reconstruction parameters (slice thickness, increment, and kernel) were equal. Tube current influences image noise, but not the calcium score. For this reason, it can be safely assumed that the different scanners did not influence coronary calcium scores. In fact, published research has shown that calcium scores are very stable across different scanner technologies $(29,30)$. For the identification and quantification of the coronary calcification using the Agatston score (AS), the datasets were transferred to an off-line image analysis workstation (Multimodality, Siemens Healthcare). In women of reproductive age, a pregnancy test was performed before the CT scan.

\section{Control group}

Fifty subjects (two for each acromegalic patient) matched for sex, age, and coronary risk factors (diabetes, smoking status, dyslipidemia, hypertension, and family history) were selected from a local electronbeam computed tomography (EBT) database that includes 5806 subjects of the Department of Cardiology. None of the 50 control subjects selected complained about angina, or had known or documented CAD, and none suffered from acromegaly according to selfreported medical history. In addition, the age-adjusted coronary artery calcium (CAC) score percentiles were calculated in patients and in controls referring to the HNR study (22).

\section{Hormone assays}

GH and IGF1 were measured by chemiluminescence assays on the Immulite 2000 (Siemens, Erlangen, Germany). IGF1 s.D. was calculated using a sex- and age-specific reference table provided by the manufacturer. All other parameters were determined by routine laboratory methods in the central clinical chemistry laboratory.

\section{Statistical analysis}

Statistical analyses were performed with SPSS software for Windows (version 14.0, SPSS Inc., Chicago, IL, USA). Data are given as the mean \pm s.D. for quantitative variables. $P<0.05$ was considered significant. The Mann-Whitney $U$ test was used for the comparisons between patients and controls, and the $\chi^{2}$ test was used for comparing the distribution of categorical data. The Spearman's rank correlation test was used to analyze the correlation between variables. Comparison of paired variables was performed by the Wilcoxon test for paired data. The major determinants of CAC in acromegalic patients were assessed by backward linear regression analysis.

\section{Results}

The clinical and endocrine findings of 25 newly diagnosed acromegalic patients are given in Table 1. The estimated duration of acromegaly was $7.1 \pm 3.0$ years. The patients were on average overweight, four patients had diabetes (16\%), ten had hypertension (40\%), 15 suffered from hypercholesterolemia (60\%), seven were current smokers $(28 \%)$, and five had a positive family history for CAD $(20 \%)$. None of the patients complained about symptoms suggesting CAD. Nineteen patients who were regularly seen at our institution were re-investigated after $4.6 \pm 1.1$ years (Table 2). At the time of re-evaluation, acromegaly was controlled in all 19 patients according to their IGF1, which was within the age- and sex-adjusted reference range. Endocrine parameters associated with disease activity significantly improved, while the overall CAD risk profile remained the same (Table 2).

\section{Ten-year risk for developing CAD (ESC risk score) in active acromegaly}

According to the ESC risk score, 21 acromegalic patients $(84 \%)$ were classified as having a low risk $(<10 \%)$, while four patients were at high risk for CAD $(>20 \%)$ because of diabetes mellitus. The ESC risk score did not correlate with the extent of GH and/or IGF1 excess, or duration of disease (data not shown). 
Table 1 Clinical and endocrine characteristics of 25 consecutive untreated active acromegalic patients and 50 sex-, age-, and coronary risk factor-matched controls.

\begin{tabular}{|c|c|c|c|}
\hline & Patients $(n=25)$ & Controls $(n=50)$ & $P$ value \\
\hline Age (years) & $45.1 \pm 10.5(29-65)$ & $44.8 \pm 9.9(28-66)$ & - \\
\hline Sex (male/female) & $10 / 15$ & $20 / 30$ & - \\
\hline BMI $\left(\mathrm{kg} / \mathrm{m}^{2}\right)$ & $28.6 \pm 5.5$ & $24.7 \pm 4.2$ & 0.002 \\
\hline $\mathrm{GH}(\mu \mathrm{g} / \mathrm{l})$ & $28+30$ & ND & - \\
\hline IGF1 (ng/ml) & $731 \pm 240$ & ND & - \\
\hline IGF1 SD & $5.7 \pm 1.5$ & ND & - \\
\hline Duration of disease (years) & $7.1 \pm 3.0$ & - & - \\
\hline Diabetes (yes/no) & $4 / 21$ & $8 / 42$ & - \\
\hline $\mathrm{SBP}(\mathrm{mmHg})$ & $130+20$ & $127+14$ & 0.818 \\
\hline $\mathrm{DBP}(\mathrm{mmHg})$ & $82 \pm 15$ & $80 \pm 14$ & 0.725 \\
\hline Hypertension (yes/no) & $10 / 15$ & $21 / 29$ & - \\
\hline Cholesterol $(\mathrm{mg} / \mathrm{dl})$ & $209 \pm 50$ & $240 \pm 57$ & 0.081 \\
\hline Triglycerides (mg/dl) & $112 \pm 35$ & $163 \pm 106$ & 0.206 \\
\hline Hypercholesterolemia (yes/no) & $15 / 10$ & $25 / 25$ & - \\
\hline Smoking (yes/no) & $7 / 18$ & $14 / 36$ & - \\
\hline Family history (yes/no) & $5 / 20$ & $12 / 38$ & - \\
\hline ESC risk (low/intermediate/high) & $21 / 0 / 4$ & $42 / 0 / 8$ & - \\
\hline AS & $2.6 \pm 7.9$ & $66 \pm 182$ & 0.012 \\
\hline
\end{tabular}

Values are mean \pm s.D.

\section{Coronary calcium content is not increased in active acromegaly compared to controls matched for age, sex, and CAD risk profile}

Coronary calcium was detected by $\mathrm{CT}$ in 5 of 25 newly diagnosed and treatment-naive acromegalic patients with a mean AS amounting to $2.6 \pm 7.9$ (range 0-31). This was significantly less than in the 50 controls matched for sex, age, and cardiovascular risk factors, of whom $48 \%$ had detectable CAC with a mean AS of $66 \pm 182$ (range 0-1013; Table 1). The prevalence of cardiovascular risk factors and the ESC risk score were identical between controls and the acromegalic patients (Table 1). The acromegalic patients were overweight
(Table 1), which, however, is unlikely to explain the results, since there is no evidence that obesity protects from CAD. CAC data (AS) from the HNR study, which comprises a large unselected population-based cohort from Germany, were used as a second independent reference cohort (14). Twenty acromegalic patients or $80 \%$ had an AS below the 25th percentile, two had an AS between the 25 and 50th percentiles, two had an AS between the 50 and 75 th percentiles, and one had an AS between the 75 and 90th percentiles of the respective sex- and age-matched HNR groups. This demonstrates lower AS values, and thus less CAC in the patients with newly diagnosed acromegaly as compared to the HNR study group. By contrast, the distribution of the AS in the

Table 2 Clinical and endocrine parameters of 19 acromegalic patients at baseline (untreated active disease) and after $4.6 \pm 1.1$ years (follow-up).

\begin{tabular}{|c|c|c|c|}
\hline & Baseline & Follow-up & $P$ value \\
\hline Age & $42.7 \pm 10.3(29-65)$ & $47.2 \pm 10.3(34-70)$ & - \\
\hline Sex (male/female) & $8 / 11$ & $8 / 11$ & - \\
\hline BMI $\left(\mathrm{kg} / \mathrm{m}^{2}\right)$ & $27.8+5.4$ & $29.1+8.1$ & 0.334 \\
\hline $\mathrm{GH}(\mu \mathrm{g} / \mathrm{l})$ & $30.4 \pm 35.1$ & $2.1 \pm 2.0$ & $<0.001$ \\
\hline $\mathrm{GH}_{\min }$ OGTT $(\mu \mathrm{g} / \mathrm{l})$ & $36.5 \pm 61.7$ & $1.1 \pm 1.4$ & $<0.001$ \\
\hline IGF1 (ng/ml) & $742 \pm 248$ & $191 \pm 65$ & $<0.001$ \\
\hline IGF1 SD & $5.7 \pm 1.5$ & $0.5 \pm 1.4$ & $<0.001$ \\
\hline Duration of disease (years) & $6.1+2.9$ & $10.6+3.0$ & - \\
\hline Diabetes (yes/no) & $2 / 17$ & $2 / 17$ & 1.000 \\
\hline $\mathrm{SBP}(\mathrm{mmHg})$ & $127 \pm 12$ & $127 \pm 15$ & 0.587 \\
\hline $\mathrm{DBP}(\mathrm{mmHg})$ & $79 \pm 11$ & $80 \pm 13$ & 0.950 \\
\hline Hypertension (yes/no) & $5 / 14$ & $6 / 1 \overline{3}$ & 0.500 \\
\hline Cholesterol (mg/dl) & $208 \pm 38$ & $215 \pm 32$ & 0.355 \\
\hline Triglycerides (mg/dl) & $114 \pm 35$ & $98 \pm 33$ & 0.080 \\
\hline Hypercholesterolemia (yes/no) & $10 / 9$ & $13 / 6$ & 0.254 \\
\hline Smoking (yes/no) & $6 / 13$ & $6 / 13$ & 1.000 \\
\hline Family history (yes/no) & $3 / 16$ & $3 / 16$ & 1.000 \\
\hline ESC risk (low/intermediate/high) & $17 / 0 / 2$ & $17 / 0 / 2$ & 1.000 \\
\hline AS & $1.7 \pm 6.0$ & $6.0 \pm 13.7$ & 0.173 \\
\hline
\end{tabular}

Values are mean \pm s.D. 
control group was similar to the HNR cohort $(<25$ th, 26 subjects; 25-50th, three subjects; 50-75th, seven subjects; 75-90th, eight subjects; $>$ 90th, five subjects).

In the acromegalic patients and in the matched control group, AS was positively correlated with the calculated ESC risk (Fig. 1, $r=0.479, P<0.015$ and $r=0.539, P<0.001$ respectively). Acromegalic patients with a positive family history $(P=0.032)$ had a higher CAC, whereas other risk factors (smoking, diabetes, hypertension, or hypercholesterolemia) were not associated with increased CAC, which might be due to the low number of patients. In the acromegalic patients, there was no association between the AS and parameters of $\mathrm{GH}$ excess or the duration of disease. In a backward linear regression analysis comprising age, sex, all conventional CAD risk factors, and parameters of $\mathrm{GH}$ excess, the final model included only age and sex as the most important determinants of AS in acromegaly.

\section{CAD risk and CAC in patients with controlled acromegaly after 4.6-year follow-up}

In the 19 acromegalic patients, who were either surgically cured or medically controlled, the CAD risk did not change according to the ESC risk score or to individual risk factors (Table 2). None of the patients reported symptoms suggestive for $\mathrm{CAD}$ or presented with major cardiovascular events during follow-up. The course of the AS in the individual patients is depicted in Fig. 2. In 13 patients, the AS remained 0, in one patient, CAC was no longer detectable, and in five patients, the AS increased. On average, the AS increased by 4.3 points, which was statistically not significant (Table 2). There was no difference in the AS neither at baseline nor during follow-up between patients, who were surgically cured or who required further medical treatment (data not shown).

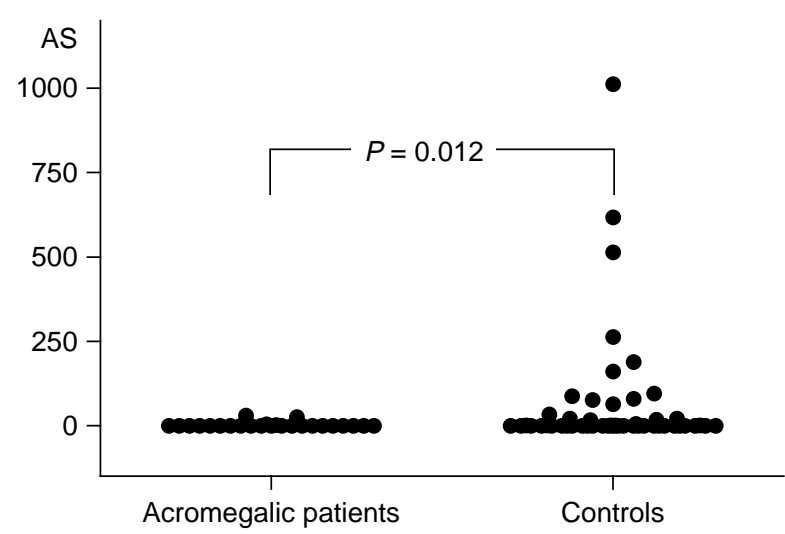

Figure 1 The AS in 25 untreated patients with active acromegaly and in 50 control subjects matched for age, sex, BMI, hypercholesterolemia, diabetes, hypertension, smoking status, family history, and the ESC risk factor score.

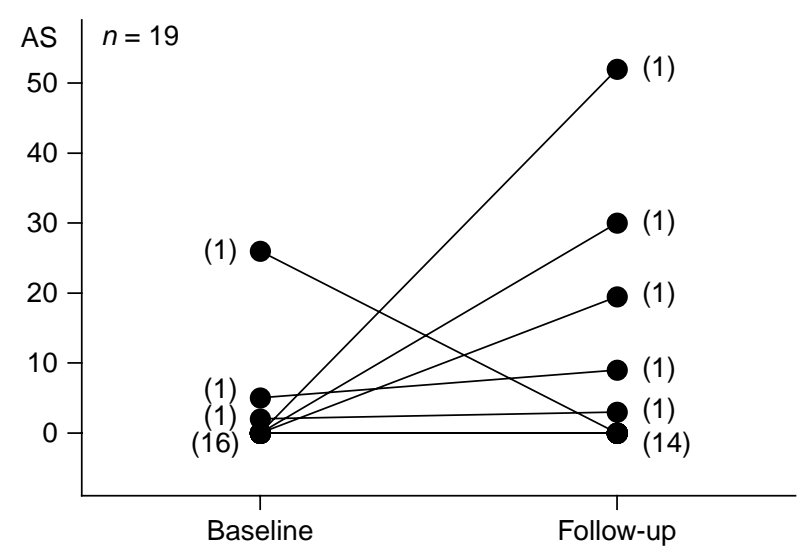

Figure 2 Preoperative AS in 19 acromegalic patients with active disease and after $4.6 \pm 1.1$ years. At the follow-up investigation, all acromegalic patients were in remission either with $(n=8)$ or without $(n=11)$ medical treatment. Numbers in brackets denote the number of patients represented by the symbol at baseline and at follow-up.

\section{Echocardiographic evaluation at baseline and during follow-up}

At diagnosis, 15 of the 25 patients had echocardiographic signs of LVH. All patients had normal LV systolic function. Main echocardiographic parameters of the subgroup of 19 patients at the time of diagnosis and during follow-up are given in Table 3. Twelve of 19 patients demonstrated LVH, which in six patients had reversed at the time of re-investigation, while in one patient mild signs of LVH had newly developed. On average, LVMi and IVS had decreased significantly at the follow-up examination (Table 3). There were no correlations between parameters of GH and/or IGF1 excess or individual coronary risk factors and the echocardiographic results (data not shown).

\section{Discussion}

In acromegaly, cardiac complications are common and cardiovascular events are the leading cause of death $(1,2)$. Many patients are exposed to coronary risk factors like arterial hypertension, diabetes mellitus, or dyslipidemia promoted by chronic GH excess $(1,5)$. Information about $\mathrm{CAD}$ in acromegalic patients is limited and controversial (1, 5-9, 14-16). Many studies investigated heterogeneous cohorts that included treatment-naive acromegalic patients, patients with uncontrolled and treatment-resistant disease, and patients in remission who were with or without various treatment regimens. Patient's risk factors might change after medical or surgical treatment of acromegaly, and in some patients, even GH deficiency could develop (31, 32), which is known to associate with an adverse cardiovascular risk profile and early atherosclerosis $(33,34)$. 
Table 3 Echocardiographic findings in 19 acromegalic patients at study entry (untreated active disease) and during follow-up (controlled disease).

\begin{tabular}{lccc}
\hline & Baseline & Follow-up & $P$-value \\
\hline Heart rate $(\mathrm{bpm})$ & $75 \pm 9$ & $62 \pm 10$ & 0.002 \\
SBP $(\mathrm{mmHg})$ & $127 \pm 12$ & $127 \pm 15$ & 0.587 \\
DBP $(\mathrm{mmHg})$ & $79 \pm 11$ & $80 \pm 13$ & 0.950 \\
IVS $(6-12 \mathrm{~mm})$ & $11.9 \pm 1.7$ & $11.0 \pm 1.6$ & 0.031 \\
LVPWT $(6-13 \mathrm{~mm})$ & $11.4 \pm 1.6$ & $10.6 \pm 1.8$ & 0.026 \\
LVM $(\mathrm{g})$ & $176 \pm 27$ & $167 \pm 25$ & 0.071 \\
LVMi $\left(\mathrm{g} / \mathrm{m}^{2}\right)$ & $91 \pm 13$ & $86 \pm 13$ & 0.022 \\
LVH $(\mathrm{yes} / \mathrm{no})$ & $12 / 7$ & $7 / 12$ & 0.097 \\
LVEDD $(33-56 \mathrm{~mm})$ & $45 \pm 4$ & $48 \pm 6$ & 0.018 \\
LVEF $(\%)$ & $>60$ & $>60$ & 1.000 \\
\hline
\end{tabular}

Values are mean \pm S.D.

The present study was therefore restricted to newly diagnosed and treatment-naive acromegalic patients in order to obtain a more homogeneous group. This, however, resulted in a study group that was somewhat smaller than the ones in previous investigations $(14,15)$. Disease duration was on average 7 years, and $80 \%$ had a macroadenoma, both of which are indicative of long standing GH excess. The frequency of concomitant complications was similar to other acromegalic cohorts investigated at the time of diagnosis $(10,15,35,36)$. The 10-year CVD risk as estimated by the ESC risk score was low in the majority of patients, and the risk was regarded as high $(>20 \%)$ in four patients because of diabetes. This is consistent with a recent report (15) but is in contrast to another study which reported that up to $41 \%$ of acromegalics were at risk for CAD (14). The two studies investigated heterogeneous groups of acromegalics with only 5 (14) or 13 (15) newly diagnosed and untreated acromegalic patients. Accordingly, the patients in those two studies were almost 10 years older than the ones in our study. Age, heterogeneous disease states, and the risk scores used (ESC versus FS) may explain the observed differences in estimated CVD risk. We used the ESC risk score because it has been developed and evaluated on European populations, and thus may better reflect environmental and lifestyle factors of our patients $(23,24)$.

Eighty percent of the newly diagnosed acromegalic patients had no detectable coronary calcium, which is consistent with the low overall CVD risk as predicted from the ESC risk score. The AS was positively correlated with the ESC risk score, like in the matched controls, and acromegalic patients with a positive family history for CVD had a significantly higher AS. Thus, in acromegalic subjects as in nonacromegalic subjects, conventional CVD risk is associated with CAC as a surrogate parameter for CAD. By contrast, parameters of $\mathrm{GH}$ excess or the duration of disease was not associated with $\mathrm{CAC}$, and linear regression analysis revealed only age and sex as the most important determinants of AS in our acromegalic cohort. Therefore, age differences of the study populations might explain the low rate of a positive AS in our newly diagnosed patients compared to previous CAC studies (14-16).

CAC in our acromegalic patients was significantly lower than that in the control group matched for age, sex, and cardiovascular risk factors at a ratio of two controls for one acromegalic patient. The controls were chosen from a cardiac CT database comprising 5490 people from the same region to further control for potential regional environmental confounders other than the conventional risk factors. The CAC data were also evaluated using reference values from the population-based HNR study, which encompasses CAC data from 4275 men and women in Germany (22). The acromegalic patients had a similar CVD risk profile, but a higher prevalence of diabetes mellitus. Despite this, $80 \%$ of the acromegalic patients had an AS below the 25th percentile of the HNR cohort. By contrast, the distribution of AS percentile values in the matched controls was as expected from the HNR study demonstrating that our matched control group reflected the AS distribution in the general population. Thus, there was no evidence for an increased CVD risk or premature $\mathrm{CAD}$ in patients with newly diagnosed and treatment-naive acromegaly. This is consistent with an earlier study that demonstrated that the prevalence of atherosclerotic plaques in the common and internal carotid arteries was not higher than in controls (37).

The present data may even suggest that acromegalic patients at the time of diagnosis are less affected by CAD than expected from the CAD risk profile in the general population. The patients' mean age was 45 years. In this age group, the background risk for CAD is low. While this is of advantage to show a potential CAD-promoting effect of GH and/or IGF excess, it is less suited to demonstrate an antiatherogenic effect. Thus, the data in that sense should be interpreted with caution, especially since the number of patients is still small. Nevertheless, our results are consistent with previous reports suggesting protection from rather than promotion of atherosclerosis and CAD in acromegaly. In one autopsy study, it was noted that only $11 \%$ of cases had CAD, which was less than expected from the patients' age (9). In a more recent study, intima-media thickness in acromegalic patients was significantly lower than in age-, sex- and risk factor-matched controls (13). Indirect evidence to support this hypothesis comes from adult-onset $\mathrm{GH}$ deficiency, which is associated with an adverse cardiovascular risk profile and early atherosclerosis $(33,34)$. GH substitution improves markers of atherogenesis $(38,39)$ and reverses early atherosclerotic changes (40). Furthermore, GH treatment presumably via IGF1 enhances nitric oxide bioavailability and increases circulating endothelial progenitor cells, which are involved in vascular function and repair 
(41). It is unknown whether these antiatherogenic actions of GH and/or IGF1 extend to the supraphysiological concentrations circulating in the acromegalic patient.

Prospective data on the progress of CAD in acromegaly are limited (15), and we are the first to consecutively evaluate $\mathrm{CAC}$ on top of CAD risk in acromegalic patients. After 4.6 years of successful treatment, the ESC risk did not change, CAC remained stable in the majority of patients, and none of the patients developed symptomatic CAD or suffered from a cardiovascular event. Because of the low number of patients, we cannot exclude that overall small and significant changes in CAC occur in these subjects, e.g. caused by aging. Furthermore, we also cannot comment whether the course of AS is similar to or less than expected from nonacromegalic subjects with a similar CAD risk profile. To assess the long-term CAD risk of acromegalic patients, further prospective studies are required ideally including an age-, sex-, and CAD riskmatched control cohort.

Echocardiography demonstrated signs of LVH in the majority of patients at the time of diagnosis. This confirms earlier studies showing that hypertrophy is the most common cardiac complication, which can occur even after relatively short-term exposure to GH excess (3-5). Upon treatment, cardiac hypertrophy was reversible in about $50 \%$ of the patients, which again is in good agreement with previous reports $(35,36,42)$.

In summary, CAD risk in acromegaly at the time of diagnosis is low, and we provide evidence that acromegaly per se does not pose an additional risk on top of known CAD risk factors. Upon successful treatment, $\mathrm{CAD}$ risk did not change, and in the majority of patients, $\mathrm{CAD}$ as evidenced by $\mathrm{CAC}$ remained stable over 4-5 years. Whether GH and/or IGF excess is even protective against $\mathrm{CAD}$, as suggested by a lower CAC in the acromegalic patients than predicted on the basis of their risk profile, remains to be shown in future studies. There appears no need for a special program for early diagnosis and routine surveillance of CAD in acromegalic patients other than that delineated from their individual conventional CAD risk profile. Risk evaluation and preventive strategies should follow the same guidelines as in nonacromegalic subjects. In contrast, echocardiographic evaluation to assess early signs of acromegalic cardiomyopathy seems to be justified at the time of diagnosis.

\section{Declaration of interest}

The authors declare that there is no conflict of interest that could be perceived as prejudicing the impartiality of the research reported.

\section{Funding}

This research did not receive any specific grant from any funding agency in the public, commercial, or not-for-profit sector.

\section{References}

1 Colao A, Ferone D, Marzullo P \& Lombardi G. Systemic complications of acromegaly: epidemiology, pathogenesis, and management. Endocrine Reviews 200425 102-152.

2 Holdaway IM, Bolland MJ \& Gamble GD. A meta-analysis of the effect of lowering serum levels of GH and IGF-1 on mortality in acromegaly. European Journal of Endocrinology 2008 159 89-95.

3 Thuesen L, Christensen AE, Weeke J, Orskov H \& Hennigsen P. The cardiovascular effects of octreotide treatment in acromegaly: an echocardiographic study. Clinical Endocrinology 198930 619-625.

4 Fazio S, Cittadini A, Sabatini D, Merola B, Colao A, Biondi B, Lombardi G \& Saccà L. Evidence for biventricular involvement in acromegaly: a Doppler echocardiographic study. European Heart Journal 199314 26-33.

5 Lombardi G, Galdiero M, Auriemma RS, Pivonello R \& Colao A. Acromegaly and the cardiovascular system. Neuroendocrinology 200683 211-217.

6 Hejtmancik MR, Bradfield JY \& Herrmann GR. Acromegaly and the heart: a clinical and pathologic study. Annals of Internal Medicine 195034 1445-1456.

7 Courville C \& Mason VR. The heart in acromegaly. Archives of Internal Medicine 193861 704-713.

8 Goldberg MB \& Lisser H. Acromegaly: a consideration of its course and treatment. Journal of Clinical Endocrinology 19422 $477-501$.

9 Lie JT \& Grossman SJ. Pathology of the heart in acromegaly: anatomic findings in 27 autopsied patients. American Heart Journal $198010041-52$.

10 Brevetti G, Marzullo P, Silvestro A, Pivonello R, Oliva G, Di Somma C, Lombardi G \& Colao A. Early vascular alterations in acromegaly. Journal of Clinical Endocrinology and Metabolism 2002 87 3174-3179.

11 Ferns GA, Motani AS \& Anggard EE. The insulin-like growth factors: their putative role in atherogenesis. Artery $1991 \mathbf{1 8}$ 197-225.

12 Balaram SK, Agawal DK \& Edwards JD. Insulin like growth factor1 activates nuclear factor-kappaB and increases transcription of the intercellular adhesion molecule-1 gene in endothelial cells. Cardiovascular Surgery 19997 91-97.

13 Otsuki M, Kasayama S, Yamamoto H, Saito H, Sumitani S, Kouhara H, Saitoh Y, Ohnishi T \& Arita N. Characterization of premature atherosclerosis of carotid arteries in acromegalic patients. Clinical Endocrinology 200154 791-796.

14 Cannavo S, Almoto B, Cavalli G, Squadrito S, Romanello G, Vigo MT, Fiumara F, Benvenga S \& Trimarchi F. Acromegaly and coronary disease: an integrated evaluation of conventional coronary risk factors and coronary calcifications detected by computed tomography. Journal of Clinical Endocrinology and Metabolism 200691 3766-3772.

15 Bogazzi F, Battolla L, Spinelli C, Rossi G, Gavioli S, Di Bello V, Cosci C, Sardella C, Volterrani D, Talini E, Pepe P, Falaschi F, Mariani G \& Martino E. Risk factors for development of coronary heart disease in patients with acromegaly: a five-year prospective study. Journal of Clinical Endocrinology and Metabolism 200792 4271-4277.

16 Herrmann BL, Severing M, Schermund A, Berg C, Budde T, Erbel R $\&$ Mann K. Impact of disease duration on coronary calcification in patients with acromegaly. Experimental and Clinical Endocrinology and Diabetes 2009117 417-422.

17 Agatston AS, Janowitz WR, Hildner FJ, Zusmer NR, Viamonte M Jr \& Detrano R. Quantification of coronary artery calcium using ultrafast computed tomography. Journal of the American College of Cardiology 199015 827-832.

18 O'Rourke RA, Brundage BH, Froelicher VF, Greenland P, Grundy SM, Hachamovitch R, Pohost GM, Shaw LJ, Weintraub WS \& Winters WL Jr. American College of Cardiology/ American Heart Association Expert Consensus Document on 
electron-beam computed tomography for the diagnosis and prognosis of coronary artery disease. Journal of the American College of Cardiology 200036 326-340.

19 Rumberger JA, Simons DB, Fitzpatrick LA, Sheedy PF \& Schwartz RS. Coronary artery calcium area by electron-beam computed tomography and coronary atherosclerotic plaque area. A histopathologic correlative study. Circulation 199592 2157-2162.

20 Rumberger JA, Brundage BH, Rader DJ \& Kondos G. Electron beam computed tomographic coronary calcium scanning: a review and guidelines for use in asymptomatic persons. Mayo Clinic Proceedings 199974 243-252.

21 Detrano R, Guerci AD, Carr JJ, Bild DE, Burke G, Folsorn AR, Liu K, Shea S, Szklo M, Bluemke DA, O'Leary DH, Tracy R, Watson K, Wong ND \& Kronmal RA. Coronary calcium as a predictor of coronary events in four racial or ethnic groups. New England Journal of Medicine $2008 \mathbf{3 5 8} 1336-1345$.

22 Schmermund A, Möhlenkamp S, Berenbein S, Pump H, Moebus S, Roggenbuck U, Stang A, Seibel R, Grönemeyer D, Jöckel KH \& Erbel R. Population-based assessment of subclinical coronary atherosclerosis using electron-beam computed tomography. Atherosclerosis $2006 \mathbf{1 8 5} 177-182$.

23 Conroy RM, Pyörälä K, Fitzgerald AP, Sans S, Menotti A, De Backer G, De Bacquer D, Ducimetiere P, Jousilahti P, Keil U, Njolstad I, Oganov RG, Thomsen T, Tunstall-Pedoe H, Tverdal A, Wedel H, Whincup P, Wilhelmsen L \& Grahm IM on Behalf of the SCORE Project Group. Estimation of ten-year risk of fatal cardiovascular disease in Europe: the SCORE project. European Heart Journal 200324 987-1003.

24 Graham I, Atar D, Borch-Johnsen K, Boysen G, Burell G, Cifkova R, Dallongeville J, De Backer G, Ebrahim S, Gjelsvik B, HerrmannLingen C, Hoes A, Humphries S, Knapton M, Perk J, Priori SG, Pyorala K, Reiner Z, Ruilope L, Sans-Menendez S, Scholte op Reimer W, Weissberg P, Wood D, Yarnell J \& Zamorano JL. European guidelines on cardiovascular disease prevention in clinical practice: executive summary. European Heart Journal $2007192375-2414$.

25 Third Report of the National Cholesterol Education Program (NCEP) Expert Panel on Detection, Evaluation, and Treatment of High Blood Cholesterol in Adults (Adult Treatment Panel III). Final Report. IV. General approach to treatment - goals and thresholds. Circulation 2002106 3243-3250.

26 Lang RM, Bierig M, Devereux RB, Flachskampf FA, Foster E, Pellikka PA, Picard MH, Roman MJ, Seward J, Shanewise JS, Solomon SD, Spencer KT, Sutton MS \& Stewart WJ. Recommendations for chamber quantification: a report from the American Society of Echocardiography's Guidelines and Standards Committee and the Chamber Quantification Writing Group, developed in conjunction with the European Association of Echocardiography, a branch of the European Society of Cardiology. Journal of the American Society of Echocardiography 200518 1440-1463.

27 Devereux RB. Detection of left ventricular hypertrophy by M-mode echocardiography. Anatomic validation, standardization and comparison to the other methods. Hypertension 1987 9 19-26.

28 Groen JM, Greuter MJW, Vliegenthart R, Suess C, Schmidt B, Zijlstra F \& Oudkerk M. Calcium scoring using 64-slice MDCT, dual source CT and EBT: a comparative phantom study. International Journal of Cardiovascular Imaging 200824 547-556.

29 Becker CR, Jakobs TF, Aydemir S, Becker A, Knez A, Schoepf UJ, Bruening R, Haberl R \& Reiser MF. Helical and single-slice conventional CT versus electron beam CT for the quantification of coronary artery calcification. American Journal of Roentgenology $2000174543-547$.
30 Stanford W, Thompson BH, Burns TL, Heery SD \& Burr MC. Coronary artery calcium quantification at multi-detector row helical CT versus electron-beam CT. Radiology 2004230 397-402.

31 Ronchi CL, Diavoli C, Ferrante E, Verruca E, Bergamaschi S, Ferrari DI, Corbetta S, Montefusco L, Arosio M, Ambrosi B, Spada A \& Beck-Peccoz P. Prevalence of GH deficiency in cured acromegalic patients: impact of different previous treatments. European Journal of Endocrinology 2009162 37-42.

32 Castinetti F, Morante I, Dufour H, Regis J \& Brue T. Radiotherapy and radiosurgery in acromegaly. Pituitary 200912 3-10.

33 Caroll P, Christ E, Bengtsson BA, Carlsson L, Christiansen J, Clemmons D, Hintz R, Ho K, Laron Z, Sizonenko P, Sönksen P, Tanaka T \& Thorner M. Growth hormone deficiency in adulthood and the effects of growth hormone replacement: a review. Journal of Clinical Endocrinology and Metabolism 199883 382-395.

34 Molitch ME, Clemmons DR, Malozowski S, Merriam GR, Shalet SM \& Vance ML for The Endocrine Society's Clinical Guidelines Subcommittee. Evaluation and treatment of adult growth hormone deficiency: an Endocrine Society Clinical Practice Guideline. Journal of Clinical Endocrinology and Metabolism 2006 91 1621-1634.

35 Minniti G, Moroni C, Jaffrain-Rea ML, Esposito V, Santoro A, Affricano C, Cantore G, Tamburrano G \& Cassone R. Marked improvement in cardiovascular function after successful transsphenoidal surgery in acromegalic patients. Clinical Endocrinology 200155 307-313.

36 Jaffrain-Rea ML, Minniti G, Moroni C, Esposito V, Ferretti E, Santoro A, Infusino T, Tamburrano G, Cantore G \& Cassone R. Impact of successful transsphenoidal surgery on cardiovascular risk factors in acromegaly. European Journal of Endocrinology 2003 148 193-201.

37 Colao A, Spiezia S, Cerbone G, Pivonello R, Marzullo P, Ferone D, Di Somma C, Assanti AP \& Lombardi G. Increased arterial intima-media thickness by B-M mode echodoppler ultrasonography in acromegaly. Clinical Endocrinology 200154 515-524.

38 Bollerslev J, Ueland T, Jørgensen AP, Fougner KJ, Wergeland R, Schreiner T \& Burman P. Positive effects of a physiological dose of $\mathrm{GH}$ on markers of atherogenesis: a placebo-controlled study in patients with adult-onset GH deficiency. European Journal of Endocrinology 2006154 537-543.

39 Serri O, St-Jacques P, Sartippour M \& Reiner G. Alteration of monocyte function in patients with growth hormone (GH) deficiency: effect of substitutive GH therapy. Journal of Clinical Endocrinology and Metabolism 199984 58-63.

40 Pfeifer M, Verhovec R, Zizek B, Prezelj J, Poredos P \& Clayton RN. Growth hormone $(\mathrm{GH})$ treatment reverses early atherosclerotic changes in GH-deficient adults. Journal of Clinical Endocrinology and Metabolism 199984 453-457.

41 Thum T, Fleissner F, Klink I, Tsikas D, Jakob M, Bauersachs J \& Stichtenoth DO. Growth hormone treatment improves markers of systemic nitric oxide bioavailability via insulin-like growth factor-I. Journal of Clinical Endocrinology and Metabolism 200792 $4172-4179$.

42 Colao A, Cuocolo A, Marzullo P, Nicolai E, Ferone D, Della Morte AM, Pivonello R, Salvatore M \& Lombardi G. Is the acromegalic cardiomyopathy reversible? Effect of 5-year normalization of growth hormone and insulin-like growth factor I level on cardiac performance Journal of Clinical Endocrinology and Metabolism 200186 1551-1557.

Received 8 January 2010

Accepted 7 February 2010 